\title{
Analisis Penggunaan Konsep Smart Governance dalam paradigma Smart City di Pemerintah Kabupaten Tanjung Jabung Timur
}

\author{
Ahmad Fajar Rahmatullah \\ Ilmu Pemerintahan, Universitas Muhammadiyah Yogyakarta \\ fajarrahmatullah.a@gmail.com
}

\author{
E-ISSN 2721-0642 \\ Article Info \\ Recieved: \\ May 292021 \\ Revised: \\ July 212021 \\ Accepted: \\ July 272021 \\ Doi Number \\ https://doi.org/10.37950/ijd.v3i2.87
}

\begin{abstract}
Abstrak
Penelitian ini memiliki tujuan untuk menganalisa bagaimana penggunaan smart governance di pemerintahan Kabupaten Tanjung Jabung Timur dalam paradigma smart city. Pada penelitian ini, penulis menggunakan pendekatan kualitatif deskriptif. Hasil penelitian menunjukan bahwa Pemerintah Kabupaten Tanjung Jabung Timur telah merepresentasikan penggunaan konsep smart governance dalam smart city berdasarkan indikator yang telah di jelaskan oleh Cohen Boyd yang mana pemerintah kabupaten Tanjung Jabung Timur sudah menerapkan 3 (tiga) komponen penting dalam smart governance oleh Boyd Cohen yaitu pertama adanya enabling supply $\mathcal{E}$ demand side policy (hadirnya sebuah kebijakan yang memayungi peran pemerintah, swasta dan masyarakat kota dalam mewujudkan smart city), kedua, transparency $\mathcal{E}$ open data (adanya keterbukaan informasi dan kemudahan mengakses/mendapatkan data) dan yang ketiga, ICT (information, Communication dan Technology) E E-Gov (Penyelenggaraan pemerintahan dan pelayanan masyarakat berbasis IT yang dapat diakses oleh masyarakat. Sementara itu, dalam konteks E-Gov, Aplikasi Sabak Smart Center sudah merepresentasikan 3 hal berdasarkan tipe relasi dari E-Government yaitu a) Government to Citizen (G-to-C). b) Government to Business (G-to-B). c) Government to Government (G-to-G).
\end{abstract}

Kata kunci: Smart City, Smart Governance, Pemerintah Kabupaten, Tanjung Jabung Timur. 
This study aims to analyze how the use of smart governance in the government of Tanjung Jabung Timur Regency in smart city paradigm. In this study, the author used a descriptive qualitative approach. The results of the study show that the Government of Tanjung Jabung Timur regency has represented the use of the concept of smart governance in a smart city based on the indicators described by Cohen Boyd. Where the Government of Tanjung Jabung Timur has implemented of 3 important components in smart governance by Cohen Boyd. First Enabling Supply $\mathcal{E}$ demand side policy (presence of policy that covers the role of the government, privat sector and urban communities in realizing a smart city. Second, transparency and open data (information disclosure and easy aces / getting data) third is ICT ( information, communication and technology) and e-gov (administration of IT-base government and community services that can be accessed by the public. Meanwhile, in the context of e-gov, the Sabar Smart Center application has presented 3 things based on the type of relation from egovernment is government to citizen (G-to-C), government to business (G-to-B) and government to government (G-to-G).

\section{Keywords: Smart City, Smart Governance, Government, Tanjung Jabung Timur}

\section{Pendahuluan}

Perkembangan tata kelola pemerintahan yang baik (good governance) terhadap penggunaan teknologi informasi seyogyanya diikuti pula dengan perbaikan kualitas pelayanan publik yang berbasis teknologi informasi karena apabila hal ini tidak dilakukan maka pemerintah akan sulit untuk memenuhi kebutuhan tuntutan publik dalam hal pelayanan yang menginginkan pelayanan yang lebih cepat, efektif, efisien dan transparan. Guna menghadapi tantangan perkembangan teknologi informasi, maka pengembangan sistem pemerintahan yang "smart" merupakan suatu keharusan yang tidak bisa ditawar dalam rangka memberikan pelayanan publik yang lebih berkualitas (Tobing, 2018). Darmi (2016) mengatakan bahwa untuk melaksanakan layanan yang ber-kualitas salah satu strategi pemerintah adalah menerapkan prinsipprinsip good governance dalam menjalankan roda birokrasi.

Salah satu jawaban untuk menghadapi tantangan di era teknologi adalah dikembangkannya konsep smart city. Smart city merupakan konsep pengembangan dan pemanfaatan dari teknologi informasi dan komunikasi (TIK) dalam mengolah, meningkatkan dan menghubungkan serta mengendalikan berbagai sumberdaya yang terdapat pada kota agar lebih efektif dengan mengoptimalkan teknologi informasi dan digital untuk meningkatkan kesejahteraan dan kebahagiaan masyarakat, serta meningkatkan layanan pemerintah sehingga dapat mengurangi dan menekan biaya, waktu serta tenaga (Eniyati et al., 2017; Mursalim, 2017). Caragliu dan Nijkamp (2011) dalam Rahmatullah (2020) mengatakan bahwa smart city merupakan sebuah konsep kota yang dapat memaksimalkan sumber daya manusia, sosial modal serta infrastruktur teknologi yang modern dengan tujuan menciptakan ekonomi 
berkelanjutan serta tingginya kualitas hidup, dengan manajemen SDM yang tepat guna melalui pemerintahan berbasis partisipasi masyarakatnya.

Untuk menghadapi tantangan di era teknologi adalah dikembangkannya sistem pemerintahan berbasis teknologi yang dikenal dengan istilah e-government. Konsep ini mulai terdengar di Indonesia sejak beberapa tahun terakhir hal ini sejalan dengan mulai banyaknya pemerintah Provinsi, Kabupaten dan Kota yang menerapkan e-government (Enceng. \& Hidayat, 2016; Fritz Akhmad Nuzir, 2015). Sementara itu, Odendaal (2003) dalam Gumilar (2019) mengatakan bahwa pemanfaatan e-government pada pemerintah lokal dapat meningkatkan fungsi dan manajemen kota.

Penelitian terdahulu oleh Bonde (2020) E-Government adalah penggunaan internet dalam melaksanakan penyelenggaraan pelayanan yang diberikan oleh pemerintah dengan menggunakan teknologi informasi untuk meningkatkan kinerja dari pemerintah dan memenuhi kebutuhan dari masyarakat akan transparansi dan akuntabilitas untuk mencapai tujuan dari Good Corporate Governance. E-Government digunakan untuk mempublikasikan informasi dimana pemerintah dapat berinteraksi dengan masyarakat melalui aplikasi atau web yang telah di sediakan oleh pemerintah sebagai layanan pengaduan. E-Government ini sebagai alat penyediaan informasi yang terfokus pada pelayanan publik. Lebih lanjut Bonde (2020) menyatakan bahwa perkembangan pemanfaatan teknologi informasi dan komunikasi menjadikan smart city sebagai jalan keluar dalam berbagai permasalahan yang harus di selesaikan oleh pemerintah daerah, dimulai dari air bersih, sampah, edukasi, transportasi, sosial ekonomi, bencana, kesehatan, dan informasi pelayanan publik.

Kemudian lebih lanjut Pramuningrum (2017) mengatakan bahwa Smart governance merupakan bagian atau dimensi pada smart city yang mengkhususkan pada tata kelola pemerintahan melalui adanya kerja sama antara pemerintah dan masyarakat diharapkan dapat mewujudkan tata kelola dan jalannya pemerintahan yang bersih, jujur, adil, dan demokrasi, serta kualitas dan kuantitas layanan publik yang lebih baik. Sehingga Smart governance dapat didefinisikan sebagai bagian dari tujuan smart city yang terkait dengan pelayanan publik, yaitu mengenai efisiensi yang lebih baik, kepemimpinan komunitas, bekerja secara mobilitas, dan perbaikan berkelanjutan melalui inovasi. Inovasi menjadi suatu keharusan yang mesti dilakukan agar keberadaan pemerintah menjadi bermakna di mata rakyatnya menurut Van Vierlo dalam Muchlas M. Tahir (2015:278) dalam Oktaviyani (2018) mengatakan inovasi tidak hanya penting untuk pelayanan publik tetapi juga untuk meningkatkan kapabilitas pemerintah. Hal senada disampaikan oleh Mauricio Bouskela (2016, p 135) dalam Nawawi (2019) Inovasi daerah melalui penerapan smart city pada penyelenggaraan pemerintahan di daerah merupakan salah satu kebijakan negara Indonesia untuk mensejahterakan masyarakatnya.

Sementara menurut Awaliah (2017) aplikasi berbasis mobile dapat diakses dengan mudah menggunakan smartphone pribadi masyarakat yang dapat digunakan untuk melaporkan informasi terkait pelayanan publik, mengetahui informasi dan kebijakan pemerintah dan dapat juga di akses oleh pemerintah dan stakeholder di 
pemerintahan yang dapat memberikan feedback secara langsung kepada masyarakat. Teknologi berfungsi membawa kemudahan akses informasi bagi masyarakat dan karenanya smart city merupakan sebuah program yang dapat diakses dengan cepat oleh masyarakat dengan bantuan sebuah aplikasi (Safitry et al., 2020).

Dari uraian singkat diatas, penelitian ini bertujuan untuk dapat menganalisis bagaimana penggunaan teknologi dalam menunjang proses terciptanya konsep smart city dalam konteks smart governance dalam paradigma smart city di Pemerintah Kabupaten Tanjung Jabung Timur.

\section{Kerangka Teori}

Berbicara tentang konsep smart city, smart city terdiri dari enam dimensi yaitu Smart Economy, Smart Mobility, Smart Environment, Smart People, Smart Living dan Smart governance .

Tabel.1.Dimensi Smart city

\begin{tabular}{|l|l|l|}
\hline No. & Dimensi Smart city & Indikator \\
\hline 1. & Smart Economy & $\begin{array}{l}\text { Enterpreunership and Innovation, Productivity, } \\
\text { Local And Global Interconnectedness" }\end{array}$ \\
\hline 2. & Smart Mobility & Mixed Modal Acces dan integrated ICT \\
\hline 3. & Smart Environtment & $\begin{array}{l}\text { Green Buildings, Green Energy, dan Green } \\
\text { Urban Planning }\end{array}$ \\
\hline 4. & Smart People & $\begin{array}{l}21 \text { Century Education, Individue Society, } \\
\text { Embrace Creativity }\end{array}$ \\
\hline 5. & Smart Living & Cultural facility, Safe dan Healthy \\
\hline 6. & Smart Governance & $\begin{array}{l}\text { Enabling Supply and Demand Side Policy, } \\
\text { Transparancy and Open Data, ICT and E-Gov }\end{array}$ \\
\hline
\end{tabular}

Sumber : Boyd Cohen (2013)

Kourtit \& Nijkamp (2012) menyatakan Smart city merupakan hasil dari pengembangan pengetahuan yang intensif dan strategi kreatif dalam peningkatan kualitas sosial-ekonomi, ekologi, daya kompetitif kota (Annisah, 2017). Rosalina (2014) memaparkan bahwa konsep smart city harus mampu menggunakan SDM, modal sosial, dan infrastruktur telekomunikasi modern untuk mewujudkan pertumbuhan ekonomi berkelanjutan dan kualitas kehidupan yang tinggi, dengan manajemen sumber daya yang bijaksana melalui pemerintahan berbasis partisipasi masyarakat.

Begitu pula menurut Nawawi (2019) bahwa smart city didesain agar dapat meningkatkan produktivitas masyarakat yang tinggal didaerah tersebut, dengan memanfaatkan teknologi informasi secara optimal di segenap aspek penyelenggaraan pemerintahan daerah. Tujuan utama konsep ini adalah untuk memaksimalkan pelayanan kepada warganya serta mendukung pembangunan yang berkelanjutan (Putro, 2019) 
Konsep smart governance merupakan salah satu dimensi dalam penerapan smart city. Griffinger dkk (2007:10-14) menjelaskan 6 (enam) dimensi dalam konsep smart city sebagai dasar dari penerapan smart city yang kemudian digunakan dalam menghitung indeks smart city 70 (tujuh puluh) kota di Eropa. Indikator dari Griffinger tersebut dipakai sebagai proses penilaian terhadap kota-kota yang telah menerapkan konsep smart city. European Smart Cities (www.smart-cities.eu) merangking kota-kota medium size mana saja yang telah memenuhi 6 (enam) kriteria smart city yakni smart economy, smart people, smart governance, smart mobility, smart environment dan smart living. Pada konsep tersebut dimensi smart governance terdiri dari sub dimensi Participation in decision making, public and social service, transparent governance dan political and strategis perfectives. Johnston and D. L. Hansen (2011:1-30) mengemukakan bahwa governance infrastructure is the collection of technologies, people, policies, practices, resources, social norms, and information that interact to support governing activities Smart governance infrastructures augment society's ability to organize, interact, and govern. (Nawawi et al., 2019).

Perencanaan Smart governance merupakan ujung tombak perencanaan Smart city. Karena Smart city dimulai dengan adanya smart governance. Tanpa adanya smart governance mustahil untuk mewujudkan Smart city (Scytl, 2015) Sehingga perencanaan smart governance haruslah mengacu pada konsep Smart city dan konsep perencaaan tata kelola yang banyak dikembangkan dengan cara menggunakan framework- framework yang ada (Annisah, 2017).

Smart governance merupakan bagian atau dimensi pada smart city yang mengkhususkan pada tata kelola pemerintahan. Adanya kerja sama antara pemerintah dan masyarakat diharapkan dapat mewujudkan tata kelola dan jalannya pemerintahan yang bersih, jujur, adil, dan demokrasi, serta kualitas dan kuantitas layanan publik yang lebih baik. Sehingga Smart governance dapat didefinisikan sebagai bagian dari tujuan smart city yang terkait dengan pelayanan publik, yaitu mengenai efisiensi yang lebih baik, kepemimpinan komunitas, bekerja secara mobilitas, dan perbaikan berkelanjutan melalui inovasi (Pramuningrum et al., 2016).

Dalam mewujudkan Smart governance, terdapat 3 (tiga) komponen penting pertama, Enabling supply \& demand side policy (hadirnya sebuah kebijakan yang memayungi peran pemerintah, swasta dan masyarakat kota dalam mewujudkan smart city), kedua, Transparency \& open data (adanya keterbukaan informasi dan kemudahan mengakses/mendapatkan data) dan yang ketiga, ICT (information, Communication dan Technology) \& E-Gov (Penyelenggaraan pemerintahan dan pelayanan masyarakat berbasis IT yang dapat diakses melalui. indikator smart governance berdasarkan Boyd Cohen.

Sementara itu dalam kontek E- Gov menurut Firdaus dan Sumardi (2021) EGovernment dalam pengimplementasiannya wajib adanya penggunaan ICT untuk meningkatkan hubungan antara pemerintah dengan pihak- pihak lain. Terdapat 3 tipe relasi dari E-Government yaitu (Adiwibowo \& Putri, 2016).. : a) Government to Citizen (G-to-C). b) Government to Business (G-to-B). c) Government to Government (G-to-G). 
Konsep Kota Pintar (Smart city) juga membuat layanan e- government dapat lebih cepat implikasinya kepada masyarakat (Faidati \& Khozin, 2018).

Tiga aspek utama dalam smart governance adalah penggunaan teknologi informasi dan komunikasi dalam pemerintahan, mewujudkan transparansi dan keterbukaan data, serta merumuskan kebijakan sesuai dengan kebutuhan warga (Jakarta Smart City, 2018).

\section{Metode Penelitian}

Penulis menggunakan metode deskriptif kualitatif. Menggunakan metode ini penulis berusaha untuk dapat mendeskripsikan, menganalisa serta membangun makna tentang fenomena yang ada (Sugiyono, 2013). Sementara itu, Hermawan (2019) menjelaskan bahwa penelitian kualitatif merupakan penelitian yang dilakukan dalam pengaturan tertentu yang ada dalam kehidupan nyata dengan maksud menyelidiki serta memahami fenomena dimana tujuannya untuk menyelidiki apa yang terjadi, mengapa itu terjadi dan bagaimana itu terjadi.

Pendekatan deskriptif dapat diartikan sebagai suatu cara pemecahan masalah yang diselidiki dengan menampilkan gambaran keadaan subyek atau obyek penelitian seperti individu, lembaga, kelompok dan masyarakat pada saat sekarang berdasarkan fakta yang tampak dan lain sebagainya (Nawawi, 2015). Sedangkan menurut Nazir (2013, p. 43) metode deskriptif yaitu suatu metode dalam meneliti status sekelompok manusia, suatu objek, suatu set kondisi, suatu sistem pemikiran, ataupun suatu kelas peristiwa pada masa sekarang. Tujuan dari penelitian deskriptif ini adalah untuk membuat deskripsi, gambaran atau lukisan secara sistematis, faktual dan akurat mengenai fakta-fakta, sifat-sifat serta hubungan antar fenomena yang diselidiki.

Teknik pengumpulan data menggunakan studi kepustakaan yaitu teknik pengumpulan data menggunakan berbagai literatur seperti buku, majalah, jurnal, dan laporan penelitian terdahulu. Dengan menggunakan studi pustaka diharapkan penulis dapat memperoleh informasi mengenai teknik-teknik penelitian yang akan dilakukan, dengan harapan penelitian penulis bukan hasil duplikasi. Menurut Nazir (2013, p. 79) dengan melakukan studi literatur, peneliti dapat memanfaatkan semua informasi dan pemikiran yang relevan dengan penelitian mereka.

\section{Hasil dan Diskusi}

\section{Infrastruktur Jaringan Fiber Optic}

Tahun 2008 merupakan awal mula dibangunnya jaringan e-government di pemerintah Kabupaten Tanjung Jabung Timur yang mana pengelolaannya di kerjakan oleh Bappeda hingga tahun 2016 dengan sistem jaringan menggunakan sistem wireless (radio), dengan bandwidht speed sebesar 2 Mbps menjadi 28 Mbps pada tahun 2016 (Imam s, 2020). Tidak berhenti sampai disitu, demi meningkatkan kualitas layanan internet dalam rangka perwujudan pelayanan komunikasi dan informatika yang berbasis teknologi yang berkualitas, dalam hal ini pemerintah Kabupaten Tanjung 
Jabung Timur melalui Dinas Komunikasi dan Informatika pada tahun anggaran 2017 yang lalu sudah membangun jaringan Fiber Optic. Bupati Tanjung Jabung Timur melalui Kepala Dinas Komunikasi dan Informatika yaitu Hermanto yang di kutip di laman website resmi diskominfo.tanjabtimkab.go.id mengatakan alasan dibangunnya Fiber Optic dengan harapan dapat mempermudah dan meningkatkan efisiensi penggunaan layanan internet untuk seluruh Organisasi Perangkat Daerah atau disingkat OPD.

Akan tetapi dalam proses menciptakan jaringan yang terintegrasi tersebut juga mengalami kendala. Dari 32 OPD dan 11 Kecamatan yang ada di Kabupaten Tanjung Jabung Timur baru 29 OPD yang baru rampung selesai terbangun. Sementara 3 OPD yang belum terbangun yaitu Perangkat Daerah, Dinas Tenaga Kerja dan Transmigrasi, Dinas Perpustakaan dan Arsip Daerah serta 11 Kecamatan tersebut masih menggunakan radio (Diskominfo Kabupaten Tanjung Jabung Timur, 2018). Infrastruktur jaringan fiber optik ini merupakan pondasi awal dalam menciptakan pondasi-pondasi pemerintahan yang smart di birokrasi pemerintahan Kabupaten Tanjung Jabung Timur.

\section{Kabupaten Pertama di Provinsi Jambi yang Mengelola Bandwith Terintegras}

Tidak hanya fokus pada penciptaan jaringan fiber optic, pemerintah Kabupaten Tanjung Jabung Timur dalam mengelola bandwith atau internet menggunakan alat yang dinamakan Network Management yang ada di kantor Diskominfo Kabupaten Tanjung Jabung Timur. Dimana hal tersebut bertujuan untuk melakukan monitoring terhadap network atau jaringan, traffic, dan wifi yang ada di lingkungan Pemerintah Kabupaten Tanjung Jabung Timur dengan fasilitas ruang server dan jaringan yang dilengkapi dengan Firewall untuk keamanannya (Imam s, 2020).

\section{Data Warehouse ( DWH)}

Data Warehouse (DWH) merupakan data kependudukan berbasis webservice yang di implementasikan pada pemerintah Kabupaten Tanjung Jabung timur dalam lingkup Organisasi Perangakat Daerah (OPD) serta lembaga pengguna lainnya di lingkup Pemerintah Kabupaten Tanjung Jabung Timur. Pemanfaatan data warehouse ini ditujukan untuk berbagai keperluan di OPD seperti contohnya yang sudah dikelola oleh Disdukcapil Kabupaten Tanjung Jabung Timur dalam pemanfaatan data kependudukan untuk menciptakan aplikasi yang menggunakan data penduduk seperti Aplikasi Buku Tamu Online dengan memanfaatkan DWH, dimana tamu yang datang hanya perlu memasukan NIK atau men-scan KTP Elektoniknya maka nama pemilik tersebut akan muncul.

\section{Aplikasi Sabak Smart Center}

Sabak Smart Center merupakan single portal Pemerintah Kabupaten Tanjung Jabung Timur. Aplikasi ini hadir dalam proses mendukung konsep Smart Government dalam memberikan pelayanan publik yang dapat diakses dengan cepat dan mudah dan 
menyajikan data - data lengkap dan aktual terkait dengan Kabupaten Tanjung Jabung Timur.

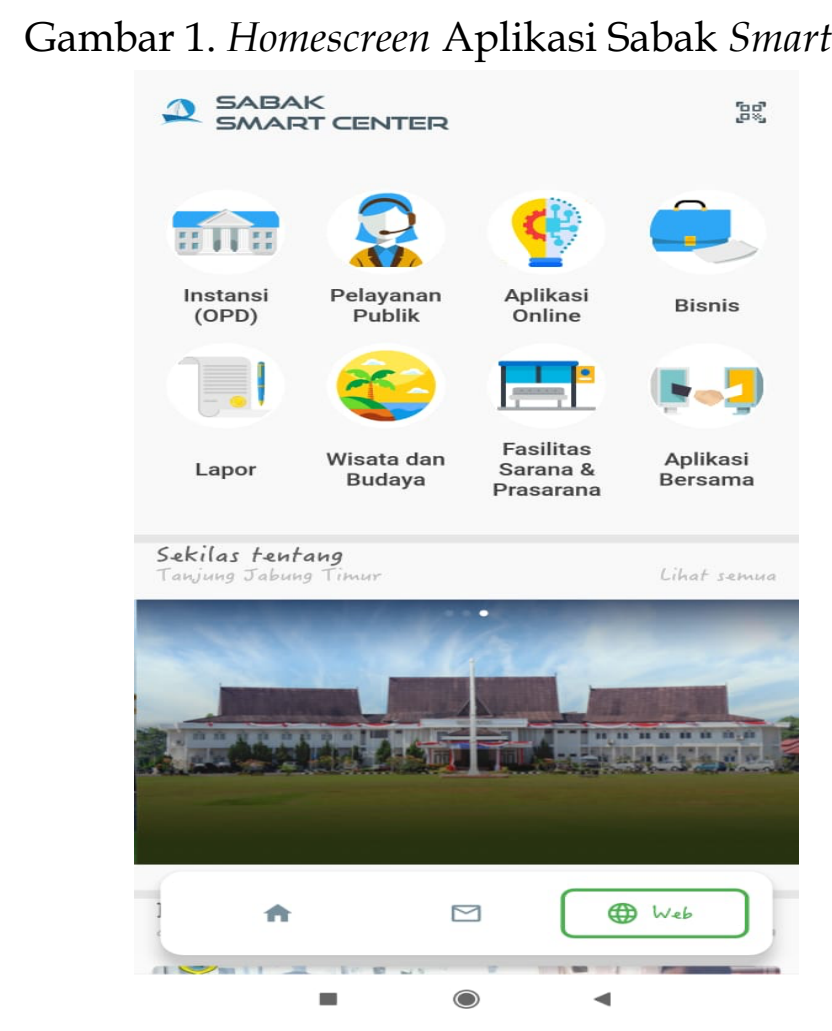

Aplikasi Sabak Smart Center ini berbasis Android dimana dengan mengakses aplikasi ini maka pengguna tidak perlu lagi untuk menghafal alamat - alamat website ataupun aplikasi Organisasi Perangkat Daerah di Kabupaten Tanjung Jabung Timur. Hal tersebut dikarenakan dengan segala fitur yang disediakan pengguna dapat dengan mudah mengakses infromasi tentang Kabupaten Tanjung Jabung Timur terutama mengenai pelayanan publik.

Aplikasi Sabak Smart Center bisa dikatakan sebagai representasi inovasi dalam bidang pemerintahan yang ada di kabupaten Tanjung Jabung Timur dimana menggabungkan segala informasi yang sangat dibutuhkan oleh masyarakat. Salah satu nya menu Instansi OPD menyajikan seluruh daftar Sekretariat, Daftar Dinas, dan Daftar Badan yang ada di Kabupaten Tanjung Jabung Timur untuk masyarkata yang ingin melakukan pelayanan.

Gambar 2. Daftar Instansi OPD yang terintegrasi dalam Aplikasi Sabak Smart Center 


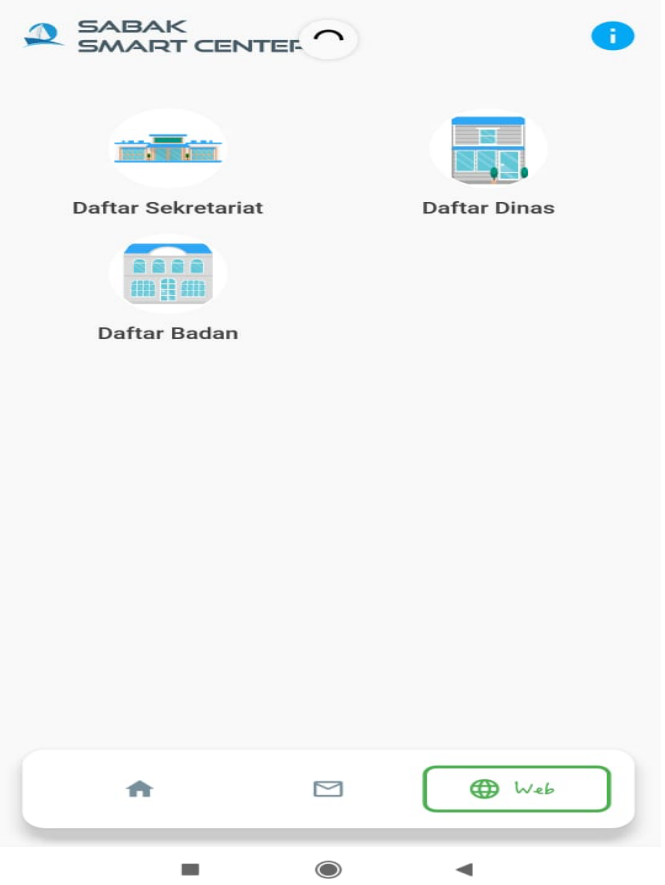

Tidak lupa pula dalam hal pelayanan publik pun segala infromasi publik dan akvitas agenda kegiatan pemerintah pun terbuka untuk diakses oleh masyarakat seperti informasi tentang Rumah Sakit Umum, Puskesmas, Kantor Polisi, Majid, Mess PKK, JDIH, dan agenda pemerintah tersedia untuk dapat di akses ke publik.

Gambar 3. Menu Pelayanan Publik

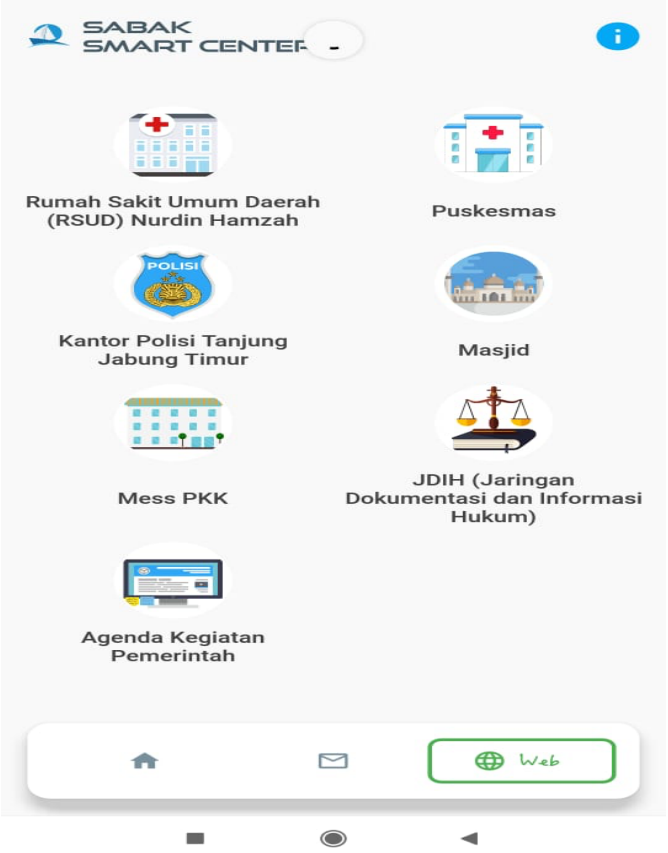

Di dalam Aplikasi Sabak Smart Center juga memuat tentang Aplikasi Online, Bisnis, Lapor, Wisata dan Budaya, Fasilitas Sarana dan Prasarana serta Aplikasi Bersama yang dapat di akses oleh warga Kabupaten Tanjung Jabung Timur ataupun masyarakat luar daerah yang ingin berkunjung ke kabupaten Tanjung Jabung Timur dalam mendapatkan informasi yang mereka butuhkan. 


\section{Kesimpulan}

Dari penjabaran diatas mengenai pengimplementasian konsep smart governance yang di implementasikan oleh Pemerintah Kabupaten Tanjung Jabung Timur dapat penulis simpulkan bahwa pemerintah kabupaten Tanjung Jabung Timur sudah menerapkan 3 (tiga) komponen penting dalam smart governance oleh Boyd Cohen yaitu pertama adanya enabling supply $\mathcal{E}$ demand side policy (hadirnya sebuah kebijakan yang memayungi peran pemerintah, swasta dan masyarakat kota dalam mewujudkan smart city), kedua, transparency $\mathcal{E}$ open data (adanya keterbukaan informasi dan kemudahan mengakses/mendapatkan data) dan yang ketiga, ICT (information, Communication dan Technology) \& E-Gov (penyelenggaraan pemerintahan dan pelayanan masyarakat berbasis IT yang dapat diakses oleh masyarakat. Dalam konteks E-Gov, Aplikasi Sabak Smart Center sudah merepresentasikan 3 hal berdasarkan tipe relasi dari E-Government yaitu a) Government to Citizen (G-to-C). b) Government to Business (Gto-B). c) Government to Government (G-to-G).

Sementara itu, implikasi penggunaan konsep smart governance di pemerintahan Kabupaten Tanjung Jabung Timur diharapkan menghasilkan kualitas pelayanan publik yang lebih baik untuk menunjang kemudahan yang diberikan dalam segala aspek, sehingga tujuan pemerintah untuk mewujudkan pemerintahan yang pintar dapat sejalan dengan keinginan dan kebutuhan masyarakat yang serba cepat.

\section{Tentang Penulis}

Penulis merupakan peneliti dari Ilmu Pemerintahan, Universitas Muhammadiyah Yogyakarta, Indonesia

\section{Ucapan Terimakasih}

Terima kasih kami ucapakan kepada Tuhan Yang Maha Esa serta pihak-pihak yang terlibat dalam penyusunan artikel jurnal ilmiah ini.

\section{Referensi}

Alawiah, E. T. (2017). Rancangan Aplikasi Smart City Berbasis Mobile Untuk Meningkatkan Kulitas Layanan Publik Studi Kasus Pemkot Bogor. Jurnal Teknik Komputer, 3(1), 24-29. https:// doi.org/10.31294/JTK.V3I1.1339

Annisah, A. (2017). Usulan Perencanaan Smart City: Smart Governance Pemerintah Daerah Kabupaten Mukomuko*. Masyarakat Telematika Dan Informasi: Jurnal Penelitian Teknologi Informasi Dan Komunikasi, 8(1), 59. https://doi.org/10.17933/mti.v8i1.103

Bonde, D. A., Purnomo, E. P., \& Salsabila, L. (2020). ANALISIS KESIAPAN KOTA 
KOTAMOBAGU DALAM MEWUJUDKAN KOTAMOBAGU SEBAGAI SMART CITY Studi: Pemerintah Daerah Kotamobagu. Moderat: Jurnal Ilmiah Ilmu Pemerintahan, 6(1), 79-92.

Boyd, C. (2013). The top 10 smart cities on the planet. https://www.fastcodesign.com/1 $679127 /$ the-top10-smart-cities- on-the- planet.

Darmi, T. (2016). PENERAPAN PRINSIP GOOD GOVERNANCE UNTUK LAYANAN PUBLIK. Jurnal Administrasi Pembangunan, 04(02), 87-156.

Diskominfo Kabupaten Tanjung Jabung Timur. (2018). Modernisasi Jaringan Internet, Pemkab Bangun Fiber Optik. Diskominfo Kabupaten Tanjung Jabung Timur. https;// diskominfo-tanjabtimkab.go.id/berita/detail/12/modernisasi-jaringaninternet-pemkab-bangun-fiber-optik

Enceng., \& Hidayat, A. (2016). PENINGKATAN LAYANAN PUBLIK MELALUI SMART GOVERNANCE DAN SMART MOBILITY. Jurnal Administrasi Pembangunan, 04(02), 87-156.

Eniyati, S., Candra, R. N., Mulyani, S., \& Martha, K. A. (2017). PERHITUNGAN TINGKAT KESIAPAN IMPLEMENTASI SMART CITY DALAM PERSPEKTIF SMART GOVERNANCE DENGAN METODE FIS MAMDANI. Jurnal DINAMIK, 22(1).

Faidati, N., \& Khozin, M. (2018). Analisa Strategi Pengembangan Kota Pintar (Smart City): Studi Kasus Kota Yogyakarta. 3(2), 16-27. https://doi.org/10.24905/jip.v3i2.1037

Firdaus, D., \& Sumardi, I. (2021). Implementasi Aplikasi e-RW untuk meningkatkan pelayanan Secara Real Time dalam mewujudkan Bandung Smart-City. Simpatik: Jurnal Sistem Informasi Dan Informatika, 1(1), 36-42.

Fritz Akhmad Nuzir, R. S. (2015). Smart People, Smart Mobility. September. https:// doi.org/10.13140/RG.2.1.3056.4324

Gumilar, M. G. (2019). Inovasi Pemerintah Daerah Jogja Smart Service Dalam Menciptakan Smart and Liveable City Di Kota Yogyakarta. Jurnal Gama Societa, $3(1), 19-27$.

Hermawan, I. (2019). Metodologi Penelitian Pendidikan (Kualitatif, Kuantitatif Dan Mixed Method). Hidayatul Quran.

Imam s, T. (2020). Ini Prestasi Kabupaten Tanjung Jabung Timur Dalam Pemanfaatan TI. Itworks. Www.itworks.id/34558/ini-prestasi-kabupaten-tanjab-timur-dalampemanfaatan-ti.html

Jakarta Smart City. (2018). Sistem Pendukung Indikator Smart Governance di Jakarta Smart City. Jakarta Smart City. https://smartcity.jakarta.go.id/blog/233/sistempendukung-indikator-smart-governance-di-jakarta-smart-city\#: :text=Tiga aspek utama dalam smart,kebijakan sesuai dengan kebutuhan warga.

Mursalim, S. (2017). Implementasi Kebijakan Smart City di Kota Bandung Siti Widharetno Mursalim IMPLEMENTASI KEBIJAKAN SMART CITY DI KOTA BANDUNG. Jurnal Bima Administrasi, https:/ / lestarinurbudi.wordpress.com/2016/06/08/ban

Nawawi. (2015). Metode Penelitian Bidang Sosial. UGM Press. 
Nawawi, M., Ilham, M., \& Setiawan, I. (2019). Analisis Penguatan Sumberdaya Daerah Dalam Pelaksanaan Smart Governance Di Kota Balikpapan, Kalimantan Timur. Jurnal Ilmiah Wahana Bhakti Praja, 9(1), 63-74. https://doi.org/10.33701/jiwbp.v9i1.320

Nazir, M. (2013). Metode Penelitian. Ghalia Indonesia.

Oktaviyani, W., \& Nugraha, J. (2018). INOVASI PEMERINTAH DAERAH DALAM PELAKSANAAN PROGRAM SMART CITY DI KOTA MAGELANG (Studi Kasus BAPPEDA Kota Magelang). Jurnal Mahasiswa Administrasi Negara (JMAN), 02(01).

Pramuningrum, A. D., \& Ali, D. S. F. (2017). Strategi City Branding Humas Pemerintah Kota Bandung Sebagai Smart City Melalui Program Smart Governance. PROMEDIA, 3(2), 162-182.

Pramuningrum, A. D., Salmiyah, D., \& Ali, F. (2016). Strategi City Branding Humas Pemerintah Kota Bandung Sebagai Smart City Melalui Program Smart Governance. 2132. www.smartcityexpo.com/in/awards-2015

Putro, D. T. W. S. (2019). ROADMAP SMART CITY KOTA MALANG. Pangripta, 1(2), 307-320.

Rahmatullah, A. F., Purnomo, E. P., \& Kasiwi, A. N. (2020). RENCANA PEMBANGUNAN JANGKA MENENGAH DAERAH KOTA JAMBI 2013-2018 SUDAHKAH MEMASUKKAN PENTINGNYA KONSEP SMART CITY. Moderat: Jurnal Ilmiah Ilmu Pemerintahan, 6(1), 125-134.

Rosalina, V., Sugiyani, Y., \& Triayudi, A. (2014). Perancangan Infrastruktur Jaringan Komputer Dalam Konsep Membangun Serang Menuju Smart City. Jurnal PROSISKO, 1(September), 44-47. https:/ / doi.org/ISSN: 2406-7733

Safitry, N., Purnomo, E. P., \& Salsabila, L. (2020). GO-JEK SEBAGAI DIMENSI SMART MOBILITY DALAM. Moderat: Jurnal Ilmiah Ilmu Pemerintahan, 6(1), 157-170.

Tobing, C. (2018). Membangun Smart Government Dalam Meningkatkan Pelayanan Publik, ditulis oleh Christian Tobing. Dinas Kependudukan Dan Pencatatan Sipil Kota Pontianak. https://disdukcapil.pontianakkota.go.id/membangun-smartgovernment-dalam-meningkatkan-pelayanan-publik-ditulis-oleh-christian-tobing 